\title{
Using Unified Theory of Acceptance and Use of Technology Model to Predict Students' Behavioral Intention to Adopt and Use E- Counseling in Ghana
}

\author{
Emmanuel Awuni Kolog ${ }^{1}$ \\ University of Eastern Finland/School of Computing, Joensuu, 8101, Finland \\ Email: emmanuk@uef.fi
}

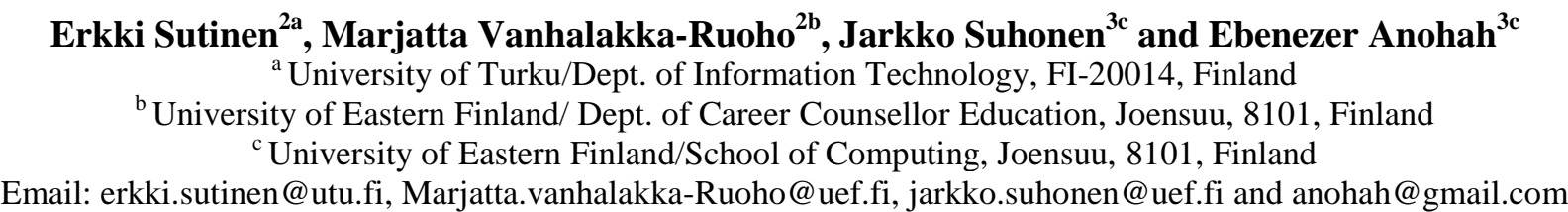

\begin{abstract}
The urge to progressively motivate ecounselling in schools is somewhat dependent on students behavioural intention towards the use of counselling technologies. This paper presents an empirical approach of using Unified Theory of Acceptance and Use of Technology model to ascertain students' behavioural intention to adopt and use e-counselling in Ghana. Questionnaires were used to collect data from two hundred and fifty $(\mathrm{N}=250)$ randomly selected students from Ghana. Cronbach alpha $(\alpha)$ was first employed to validate and ascertain the reliability of the data. Subsequently, Multiple Linear Regression (MLR) was employed in analysing the data. After that, a follow-up interview was conducted to explore the variance in our findings from the collected data through the questionnaires. In the end, the reliability of the test items contained in the questionnaire yielded strongly at $87.6 \%$. Also, whereas the outcome of the research suggests Performance Expectancy and Social Influence as the influencing constructs (factors) towards students' behavioural intention to adopt and use e-counselling, Facilitation Condition and Effort Expectancy had no effect on the behavioural intention of students to adopt and use e-counselling in Ghana. The findings shall be considered in developing e-counselling system for counselling delivery.
\end{abstract}

Index Terms-Unified Theory of Acceptance and Use of Technology (UTAUT), Counselling, e-Counselling, ICT

\section{INTRODUCTION}

Of the myriad of students' life challenges, the establishment of counselling units in schools has a tremendous benefit towards students' holistic life development. In Ghana, counselling gained prominence through its implementation in the health sector to help patients towards life decisions, anxieties and trauma [2]. It was until 1975 when Ghana Education Service saw the need to establish counselling centres in all the schools in Ghana [2]. The idea was to administer counselling to students in a bid to help them develop rapidly. Since its inception, less attention has been given to it in terms of resourcing the sector to meet students' demand for counselling, though counselling is recognized as one of the key elements of the guidance programme in Ghana. Senior High School (SHS) education in Ghana consists of both resident (boarding) and non-resident (day) students, for which all students are entitled to counselling services. In spite of school counsellors having the prerogative to administer counselling to students, the school staff also forms part of the school counselling team. Meanwhile, traditional face-to-face (f2f) counselling was, and is still the sole method on which most educational counsellors rely for counselling delivery [3]. Consequently, geographically isolated and physically challenged students are disadvantaged in accessing counselling services due to the limited scope of the face-to-face counselling. This situation is worrying considering the demand for counselling in the 21st Century.

Reference [4] view counselling in a school system as a tool for eliminating ignorance of young people towards making choices in career and for academic development. In the broader perspective, school counselling ought to help students to develop holistically [7]. Holistic model of counselling is "an integrative counselling approach which combines a wide range of counselling techniques that focus on the whole being or well-being of individuals" [3]. In this regard, the onus rests on the school counsellors to bring out the latent capabilities of students by helping them to contain the inevitable life challenges. Meanwhile, in recent times, the increasing rate of social vices such as drug abuse, increased sexual activity and campus unrest in schools [5] has become public policy 
issue and a subject of concern over the eventual ramification in National development. While many have attributed the situation to the current economic challenges of the country, others have also raised questions over the essence of counselling programs in schools.

The advance in the use of ICT in education and other related disciplines is gradually gaining roots in the African context [8] albeit with less focus on its integration into counselling. Despite the challenges associated with the implementation of ICT-mediated counselling, Reference [7] observe that changes due to the growing pace of ICT would influence individual's development. This intention highlights the relevance to integrate ICT into counselling in order to meet the increasing diverse demand for counselling. The stakeholders have come under harsh criticisms for their inability to adequately resource the Senior High School (SHS) with ICT to meet the current pace of technology. This brings to the fore the challenges that impede digital revolution. In line with that, [10] carried out a study to unravel the possible challenges of ICT implementation in the developing countries. Key findings from the discovered challenges were lack of skilled human resources and perceived difficulty in ICT integration [10].

Notwithstanding the effort by large private organizations and the government towards investing heavily in information systems research, less study has been carried out to ascertain the behavioural intentions of students to adopt and use ICT in Ghana. In spite of the need to integrate ICT into counselling, the factors that motivate students to adopt and use e-counselling cannot be overlooked. Consequently, we were motivated to take up this study. This paper however focuses on investigating students' behavioural intention towards adoption and use of e-counselling through UTAUT model. The Unified Theory of Acceptance and Use of Technology (UTAUT), a model for behavioural use and acceptance of Information Technology System was proposed and tested by [1]. The model has seen quite a remarkable usage by researchers in Educational Technology and other related disciplines. This motivates a progressive development of e-counselling in schools. The method and findings of this study can also be employed in other digital studies of education such as elearning. Prior to this study our previous studies had shown that students know and are aware of the available tools that constitute e-counselling (see: Kolog et al. 2014). This study forms part of a design science research framework towards developing e-counselling system. The four UTAUT constructs viz performance expectancy $(P E)$, effort expectancy (EE), social influence (SE), and facilitating conditions $(F C)$ have been explained below.

Performance expectancy is the degree to which an individual believes that using a particular system would improve his or her job performance.

Effort expectancy is the degree of simplicity associated with the use of a particular system.
Social influence is the degree to which an individual perceives that others believe that he or she should use a particular system.

Facilitation condition is the degree to which an individual believes that an organizational and technical infrastructure exists to support the use a particular system.

Behavioural intention is the degree to which individuals behaves to accept and use of a system.

The paper has five Sections. Section 1 takes a look at the background of the paper, elaborating on the challenges and benefits of e-counselling in Ghana. The objectives and the hypothesis formulation of the study have also been captured in Section 1. Section 2 takes a look at the ontological foundation of the research with regards to research works that have used UTAUT. In Section 3, the method on which the study was carried out have been outlined, detailing the selection of the participants. Section 4 reflects on the approach on which the collected data was analysed. This took into account the reliability and Multiple Regression approach. Finally, while Section 5 reports the findings of the research, Section 6 discusses the research findings in line with literature. The concluding part in Section 7 reflects on the outcome of the entire study and its relevance in our future study.

\section{A. Research Objectives}

1. To validate and determine the reliability of UTAUT constructs based on respective data collection.

2. To investigate the factors that drives students to adopt and use e-counselling in Ghana.

\section{B. Hypothesis Formulation}

H1- Performance Expectancy has positive influence on students' behavioural intention to use ecounselling.

H2- Effort Expectancy has positive influence on students' behavioural intention to use ecounselling.

H3- Social Influence has positive influence on students' behavioural intention to use e-counselling.

H4- Facilitation Condition has positive influence on students' behavioural intention to use ecounselling.

\section{RELATED WORK}

ICT-mediated counselling is often referred to as ecounselling [15] or online counselling [16]. E-counselling in Ghana is viewed as a digital form of receiving supportive counselling either through an exchange of emails or live webcam session over the internet [6]. The idea of e-counselling was to diversify the sector to allow people with diverse interest to access counselling services irrespective of the location and time. Thus remote (day) students, especially those who are geographically isolated and physically challenged could access counselling services efficiently. In Ghana, e-counselling gained 
prominence in 2007's educational reform in which ICT was introduced as a core subject of study in schools [17]. The aim was to propel students to acquire knowledge in ICT, which of course would motivate students to use ecounselling.

Although, the advent of ICT has made it possible for clients to vary counselling methods [14] based on choice and convenience yet few technologies have been developed contextually to meet counselling demands. Meanwhile, substantial number of Information Technology tools have been adopted in counselling delivery. Popular among these technologies are Email, Skype, video conferencing and telephone. The aforementioned technologies have existed for a long time but rarely used in the context of the Ghanaian SHS counselling sector [3]. Conversely, [13] developed a semantic web-based e-counselling system to assist students to surf for relevant information from the web, especially career and academic exploration. The study identified a problem of large volumes of irrelevant information retrieval by students from the web upon a specific query. The system was built from Natural Language Processing (NLP) approach using semantic web algorithm [13]. The key functionality of the system, according to the researchers aims at helping students to organize and sort substantial but relevant web information. In a related study, [12] developed a global web peer counselling system for clients. The system was designed to provide students with the opportunity to address each other's (peer) concerns. Also, the researchers recommended the peer counselling system to be used to offer mental healthcare services by peer counsellors.

The urge to progressively motivate e-counselling in schools is somewhat dependent on students' behavioural intention towards the use of the technology. UTAUT is a unified model developed by [1]. The model was developed through a review and validation of eight exiting theories that have the propensity to predict the behavioural intention to use Information Technology. The eight existing models are Theory of Reasoned Action (TRA), Technology Acceptance Model (TAM), Motivational Model (MM), Theory of Planned Behaviour (TPB), a combined Theory of Planned Behaviour and Technology Acceptance Model (TPB-TAM), Model of Personal Computer use and a combined Theory of Diffusion of Innovations Theory (MPC-TDIT) and SocioCognitive Theory (SCT). Before then, several researchers have explored the existing models in a bid to predict behavioural intention to adopt and use Information Technology (IT). Subsequently, [1] validated UTAUT model against the eight existing models and eventually discovered that the Unified theory (UTAUT) outperformed all the eight existing models with an impressive $70 \%$ (adjusted $\mathrm{R}$ square) of the variance in behavioural intention (BI) and about $50 \%$ in actual use. This led to the unification of the eight models to produce the UTAUT constructs viz. Performance Expectancy $(P E)$, Effort Expectancy (EE), Social Influence (SE), and Facilitation Conditions ( $F C$ ). UTUAT model is believed to be robust contemporary predictive theory for behavioural intention towards acceptance and use of information technology [1]. Given that we decided to use the Unified theory (UTAUT) against the eight existing models in this research to predict students' behavioural intention to accept and use e-counselling. While we adopted UTAUT constructs in our study, moderated variables like gender, age, experience and voluntariness of use, suggested by Venkatesh et al. [1], were not adopted in this study. Fig. 1 below is an illustration of UTAUT model consisting of the constructs and their relations.



Fig.1. UTAUT model (Venkatesh et al., 2003)

Since the inception of UTAUT, several studies have explored the theory in diverse context of studies with varying findings [18]. Researchers who adopted the UTAUT model either use the same constructs proposed by Venkatesh et al. or make changes to the constructs to suit their respective context. Reference [19] validated the model in the subject of user acceptance towards Educational Technology (ET). Conversely, the study confirms the validity and robustness of UTAUT model yet suggested that further analysis ought to be conducted to confirm UTAUT as reliable model for user acceptance and use of IT system. Also, [29] reported invariant true scores across most of the UTAUT constructs in a study conducted on user acceptance of Community weblog.

Of the widely adoption of UTAUT model, [18] gathered and reviewed several publications that have used UTAUT. The researchers discovered that, findings, as a result of the use of UTAUT vary according to diverse context of study and the Information Technology system under study. In the perspective of Educational Technology, [20] adopted UTAUT model to estimate the driving factors that influence user acceptance of web base question-answer system (WBQAS) in China. The study revealed that $\mathrm{PE}, \mathrm{FC}$ and $\mathrm{EE}$ were significant predictors of the BI to use the WBQAS. On the contrary, SI had no significant impact on the BI to use WBQAS. In a related study, [21] found EE and SI to be significant in predicting use behaviour in a study conducted in US towards describing students' perceptions of using course management software application. Also, [22] investigated whether the differences in gender, age and occupation for m-learning influences the use of mobile device. The study found out that SI has positive effect on BI to use mlearning with females having the higher influencing index. 
Reference [23] investigated the key determinants of internet banking adoption in Jordan. The researchers selected 940 participants mainly users of internet banking. UTAUT model was validated to ascertain its reliability in the study through the estimation of Cronbach coefficient. In the end, the study revealed that PE, EE, SI and FC were statistically significant in user intention towards adoption of internet banking in Jordan. Reference [24] combined UTAUT with perceived risk to explain the behavioural intention and use behaviour in internet banking. The researchers first validated UTAUT constructs and reported that UTAUT is reliably a model for a predictive research work. Subsequently, the study reported that while $\mathrm{FC}$ is insignificant in user behaviour on internet banking adoption, PE, EE, SI and risk were strong predictors of $\mathrm{BI}$, and $\mathrm{BI}$ also predicts the use behaviour of internet banking.

Moreover, [33] carried out a study to understand the attitude of "Goce Delchev" University's teachers in Macedonia towards the use of new technology and the predictive factors that motivate the teachers to accept and use eLearning system. UTAUT model was adopted. The study employed a survey of 92 teaching staff from the University on which questionnaires were used. While the researchers found $\mathrm{EE}$ and $\mathrm{FC}$ as the strongest in the use of new technology, SI and FC were found strongly correlated with the behavioural intention to use eLearning systems at the University of "Goce Delchev".

\section{METHODOLOGY}

The section introduces the methodological approach of the study. This involves the participants' settings, data collection from a designed questionnaires and collection of data through conduct of interview.

\section{A. Participant settings and Data collection}

In Ghana, the SHS Education is categorized into classes based on infrastructure, academic performance and cost of school fees, thus Class ' $A$ ', ' $B$ ', and ' $C$ '. It is obvious that the affluent students, who perform creditably well from the Junior High School are mostly found in the Class A schools followed by B which contains mostly the middle class students and then the less endowed students found in Class C. Given this analogy, we decided to select schools from each of these classes (A, B and C), thus Anglican SHS (KASS) from class 'A' schools, AGASS (Agona Seventh Day Adventist SHS) from class 'B' and BPRESEC (Presbyterian SHS, Bompata) from class ' $\mathrm{C}$ ' schools. The idea was to have a diverse opinion from all of these classes of students. Fig. 2 shows the respective number of participants from the three selected schools with particular focus on gender.

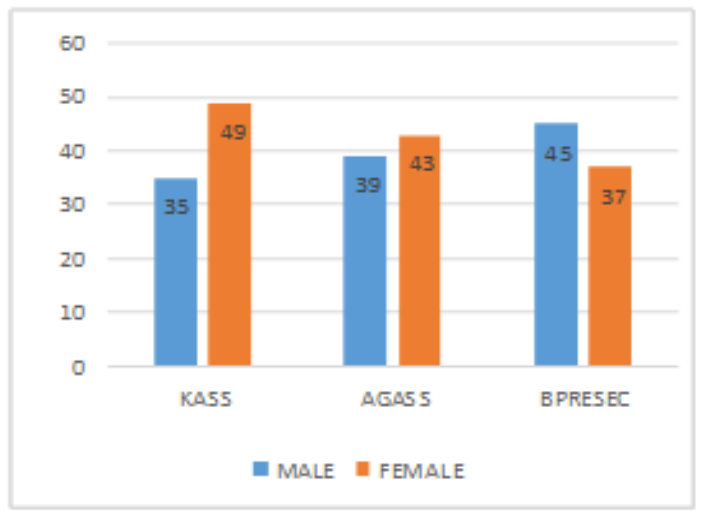

Fig.2.Selection of Participants based on Gender in each selected schools

Two hundred and fifty $(\mathrm{N}=250)$ students from the three SHSs were randomly selected for the study, of which 85 students each were selected from SHS 1 and 2 while the remaining 80 students were selected from the SHS 3 respectively. Subsequently, questionnaires which consist of mainly close-ended questions were administered to the selected students. In the end, only two hundred and fortyeight (248) questionnaires were retrieved from the selected students. The questionnaire consists of twenty (20) question items for which four of each question items were under each of the UTAUT constructs. We employed Likert scale ranging from 1 to 7 , where $1=$ completely disagree, 2 = moderately disagree, 3 = somewhat disagree, 4 = neutral (neither disagree nor agree), $5=$ somewhat agree, $6=$ moderately agree, and $7=$ completely agree. Of the collected number of questionnaires, $84(33.06 \%)$ students consisting of 35 male and 49 female students were students of KASS, 82 (33.06\%) students consisting of 39 males and 43 females were also from AGASS and lastly, 82 (33.8\%) female were students of BPRESEC. Fig. 3 shows the number students selected based on Educational levels and residential status.

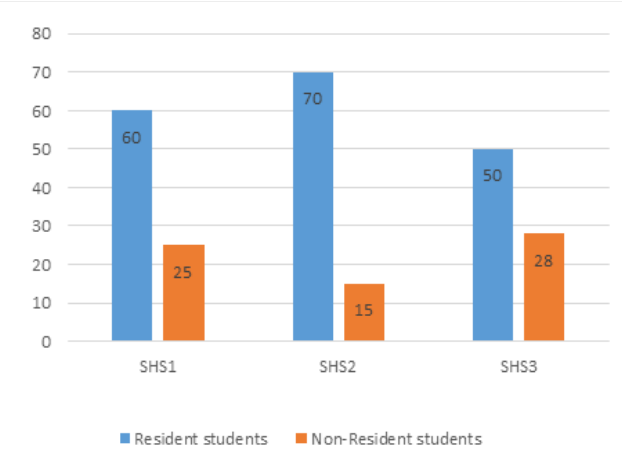

Fig.3. Number of participants based on Residential status in each levels of education 
After analysing the collected data from the questionnaire quantitatively, a follow up interview was conducted. Thus, thirty students were selected from the initially selected two hundred and fifty students for the interview. Ten (10) students each were randomly selected from the three SHSs viz. KASS, AGASS and BPRESEC. The interview focused on students' motivational factors to use e-counselling either by contextualized ecounselling system or through a counsellor in order to compare with the findings from the questionnaire. The interview was conducted in a form of unstructured interactive session. Therefore, key responses from the students were taken down in a notebook. The intention was to affirm or find the variance in our findings from the data collected through the questionnaires.

\section{Method Of ANALYSIS}

Cronbach alpha was first employed to ascertain the internal consistency (reliability) of the data. After that, Linear Multiple Regression analysis was performed to establish the significance of the various constructs in behavioural intention of students to adopt and use ecounselling in Ghana. In the end, the content of the data collected through the interview was also analysed in line with the Interpretivists philosophical paradigm.

\section{A. Descriptive statistics}

Descriptive statistics describe, show or summarize data in a meaningful way. Though descriptive statistics can be computed manually, we used Statistical Package for the Social Sciences (SPSS) 20 to compute for the mean and standard deviation of all the 20 test items and the UTAUT constructs. The mean values depict the average responses from the respondent while the standard deviation values depict the amount of variation in the data. Whereas a standard deviation value closer to 0 indicates the closeness of the data points to the mean, high standard deviation indicates the spreading out of the data points. While Table 1 illustrates the descriptive statistics of each constructs, Table 2 provides detailed descriptive statistics of all the test items.

Table 1. Descriptive statistics of the constructs

\begin{tabular}{lcr}
\hline Construct & Mean & Std. Deviation \\
\hline Performance Expectancy & 5.8407 & 1.24273 \\
Effort Expectancy & 5.7581 & 1.23950 \\
Social Influence & 5.7601 & 1.21078 \\
Facilitating Condition & 6.0655 & 1.09401 \\
Behavioural intention & 6.0716 & 1.09085 \\
\hline
\end{tabular}

Table 2. Test items under each UTAUT constructs with respective mean and standard deviation

\begin{tabular}{|c|c|c|}
\hline Test Items & Mean & Std. Dev. \\
\hline PERFORMANCE EXPECTANCY & 5.8407 & 1.24273 \\
\hline PE1: I will find e-counselling useful and efficient in counselling sessions & 5.6734 & 1.74549 \\
\hline PE2: Using e-counselling would enable me to access counselling services easily & 5.4758 & 1.92979 \\
\hline $\begin{array}{l}\text { PE3: Using e-counselling will enable me to manage time efficiently, since I can connect to a counsellor } \\
\text { everywhere at any time. }\end{array}$ & 5.7540 & 1.78840 \\
\hline $\begin{array}{l}\text { PE4: Using e-counselling would motivate me to tell about my life challenges anonymously to a counsellor } \\
\text { without been shy or fear. }\end{array}$ & 6.4597 & 1.11957 \\
\hline EFFORT EXPECTANCY & 5.7581 & $\mathbf{1 . 2 3 9 5 0}$ \\
\hline $\begin{array}{l}\text { EE1: My interaction with e-counselling services would be clear and understandable towards my academic } \\
\text { development. }\end{array}$ & 5.7661 & 1.66949 \\
\hline EE2: It is easy for me to become skilful at using e-counselling services & 5.7984 & 1.65424 \\
\hline EE3: I will find any e-counselling tools (Skype, email) easy to use & 6.1855 & 1.31246 \\
\hline EE4: Learning to operate e-counselling will be easy for me & 6.5121 & 1.06464 \\
\hline SOCIAL INFLUENCE & 5.7601 & 1.21078 \\
\hline SI1: People who influence my behaviour would think that I should use & 5.2944 & 1.92523 \\
\hline SI2: People who are important to me would think that using e-counselling is good for me & 5.3548 & 1.95990 \\
\hline SI3: My school counsellor has been encouraging me to use e-counselling & 6.0000 & 1.55076 \\
\hline SI4: In general, my school has been advocating for the use of ICT in counselling & 6.3911 & 1.24533 \\
\hline FACILITATING CONDITION & 6.0655 & 1.09401 \\
\hline FC1: I have the resources necessary to use e-counselling & 5.7661 & 1.66949 \\
\hline FC2: I have the knowledge necessary to use e-counselling & 5.8226 & 1.62744 \\
\hline FC3: E-counselling is not compatible with other systems I use & 6.1855 & 1.31246 \\
\hline FC4: A help is available for me should there be any difficulties in using e-counselling & 6.5121 & 1.06464 \\
\hline BEHAVIORAL INTENTION & 6.0716 & $\mathbf{1 . 0 9 0 8 5}$ \\
\hline BI1: I intend to use e-counselling in the future. & 5.7419 & 1.65616 \\
\hline BI2: I predict that I would use e-counselling in the future & 5.7903 & 1.62358 \\
\hline BI3: I plan to use e-counselling in the future & 6.1532 & 1.32276 \\
\hline BI4: I intend to recommend e-counselling to friends in the future & 6.5121 & 1.06464 \\
\hline
\end{tabular}

Note: Std. Dev. = Standard deviation 


\section{B. Reliability}

According to Merriam Webster dictionary, "reliability is the extent to which an experiment, test, or measuring procedure yields the same results on repeated trials". Cronbach alpha is used as an estimate for the reliability of a psychometric test [25] and has been reported as one of the most commonly reliability estimates [26]. Given that we intend to measure a quantity which is the sum of $K$ components (test items): $\mathrm{X}=\mathrm{y}_{1}+\mathrm{y}_{2}+\mathrm{Y}_{3}+\ldots \ldots .+\mathrm{y}_{\mathrm{k}}$, then Cronbach alpha $(\alpha)$ is defined as:

$$
\alpha=\frac{k}{k-1}\left(1-\frac{\sum_{i=1}^{k} \delta^{2} y_{i}}{\delta^{2} x}\right)
$$

Where $\sigma_{X}^{2}$ is the variance of the observed total test scores, and $\sigma_{Y_{i} \text { the variance of component } i \text { for the }}^{2}$ current sample of persons.

Based on definition of Cronbach alpha, we used SPSS 20 to estimate the reliability coefficients [25] for each constructs. According to [26] Cronbach alpha ranges from 0 to 1 . Some researchers have indicated that the acceptable limit for the Cronbach alpha is greater or equal to 0.6 and others have also reported 0.7. Reference [27] reported that, where the estimated value of Cronbach alpha is greater or equal to 0.7 , it implies an acceptable level of reliability, whereas any value lesser or equal to 0.7 depicts weak reliability. Table 3 represents the reliability coefficient of each constructs. The reliability coefficient for all the 20 items yielded 0.878 . This implies that the internal consistencies of all the items used in this study is $87.8 \%$ reliable.

Table 3. Cronbach alpha for internal consistencies

\begin{tabular}{lrr}
\hline Construct & Variable & Cronbach alpha \\
\hline PE & Independent & 0.728 \\
EE & Independent & 0.753 \\
SI & Independent & 0.700 \\
FC & independent & 0.750 \\
BI & Dependent & 0.722 \\
\hline For all the test items & & $\mathbf{0 . 8 7 8}(\mathbf{8 7 . 8 \% )}$ \\
\hline
\end{tabular}

\section{Estimation of the Predictive factors}

Having confirmed a strong internal consistency of the constructs shown in Table 3, we further analysed the data with Multiple Linear Regression to predict the behavioural intention of students towards the use and adoption of e-counselling in Ghana. While from the UTAUT constructs the independent variables were identified as Performance Expectancy (PE), Effort Expectancy (EE), Social Influence (SI) and Facilitation Condition (FC), Behavioural Intention (BI) was the dependent variable as shown in Table 3. Table 4 is the study's model summary obtained from SPSS 20 after the computation.

Table 4. Model summary

\begin{tabular}{rrrrr|rrrrr}
\hline Model & R & R Square & $\begin{array}{r}\text { Adjusted R } \\
\text { Square }\end{array}$ & $\begin{array}{r}\text { Std. Error of } \\
\text { the Estimate }\end{array}$ & \multicolumn{4}{c}{ Change Statistics } \\
\hline & & & & & R Square Change & F Change & df1 & df2 & Sig. F Change \\
\hline 1 & $.797^{\mathrm{a}}$ & .636 & .630 & .66369 & .636 & 106.067 & 4 & 243 & $\mathbf{. 0 0 0}$ \\
\hline
\end{tabular}

Dependent Variable: $B I$

Independent Variable: (Constant), FC, EE, SI, PE

Table 5. ANOVA table showing the overall significance of the model

\begin{tabular}{crrrrr}
\hline & Sum of Squares & df & Mean Square & F & Sig. \\
\hline Regression & 186.881 & 4 & 46.720 & 106.067 & $\mathbf{. 0 0 0}^{\mathbf{b}}$ \\
Residual & 107.036 & 243 & .440 & & \\
Total & 293.917 & 247 & & & \\
\hline
\end{tabular}

Dependent Variable: BI

Independent Variable: (Constant), FC, EE, SI, PE

Table 6. Regression coefficients.

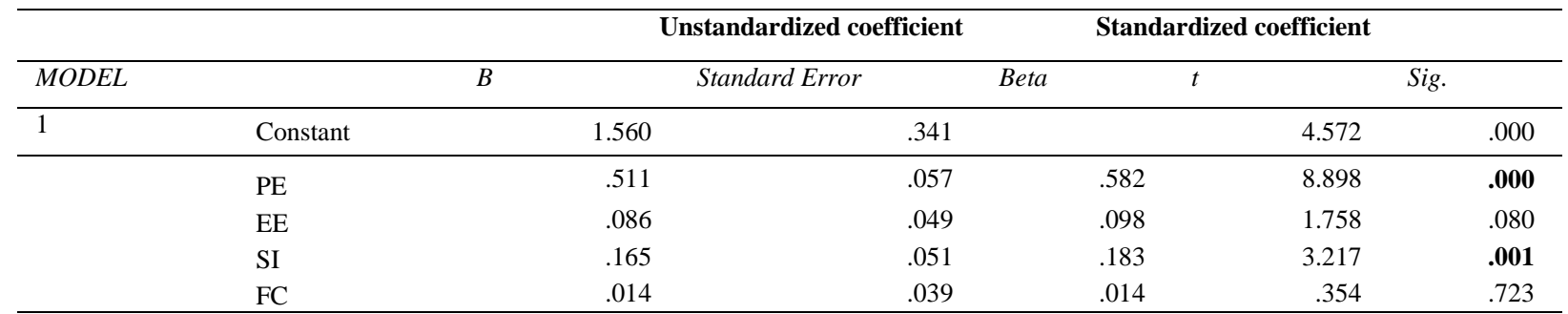

Note: significance is $p<.005$

Dependent Variable: $B I$ 
Given Multiple Linear Regression equation:

$$
Y_{i}^{\prime}=b_{0}+b_{1} X_{1 i}+b_{2} X_{2 i}+\ldots+b_{k} X_{k i}
$$

Where the " $b$ " values are called regression weights, "Y" depicts the dependent variable and " $x$ " represents the independent variables, we have, from Table 6, deduced the regression model shown in equation (3) based on equation (2). Since p-values for FC and EE are statistically insignificant we can consider removing from the model.

$$
B I=1.560+.086(E E)+.014(F C)+.165(\mathrm{SI})+.511(\mathrm{PE})
$$

Equation (3) shown above represents MLR equation of the model (unstandardized). This indicates the relation between the dependent and the independent variable. Hence, from equation (3), whereas the PE and SI are significant in determining the dependent variable (BI), $\mathrm{EE}$ and $\mathrm{FC}$ are insignificant in determining the dependent variable (BI).

\section{FINDINGS}

For having analysed the content of the data collected based on the adopted constructs from UTAUT, this Section reports the findings. Hence, the Section contains Sub-Section A and B, which reports the findings from the questionnaires and the interviews of the participants.

\section{A. Findings from the questionnaire}

The first objective of this study is to determine the reliability of the collected data based on UTAUT model. From Table 3, the overall internal consistency of the model yielded 0.878 which depicts $87.8 \%$ reliability. This shows a strong internal consistency for all the UTAUT constructs. However, the reliabilities of individual construct were also computed. In the end, Performance Expectancy (PE) yielded 0.728 indicating $72.8 \%$ of internal consistency, Effort Expectancy (EE) yielded 0.753 , representing $75.3 \%$ internal consistency, Social Influence (SI) gave a reliability coefficient of 0.7 depicting $70 \%$, Facilitation Condition yielded 0.750 depicting $75.0 \%$ reliability and behavioural intention (BI) yielded 0.722 depicting $72.2 \%$ of internal consistency.

From Table 5, the p-value of the overall model is .000 . The value implies that the probability of $\mathrm{F}$ statistic (106.067) of the overall regression relationship is $<0.001$ and less than or equal to the level of significance of 0.05 . This implies that the full model is statistically significant $(\mathrm{F}=106.607, \mathrm{df}=243,4, \mathrm{sig} .=.000)$. Also, from Table 4 , the overall Multiple R for the relationship between the set of independent variables and the dependent variable is 0.797 while the Adjusted R Square is 0.630 . Therefore, the value of the overall model is significant which clearly explains $63.0 \%$ of the variance in students' behavioural intention to adopt and use e-counselling in Ghana.

Regarding the individual constructs, the MLR model with all the four constructs produced $\mathrm{R}^{2}=.636, \mathrm{~F}(4,243)$
$=106.067$ and less than or equal to the level of significance of 0.05 . As this can be seen in Table 6, the Performance Expectancy ( $\mathrm{p}$ value $=.000)$ and Social Influence $(\mathrm{p}$ value $=.001)$ had significant regression weights, indicating that the hypothesis (claim) $\mathrm{H}_{1}$ and $\mathrm{H}_{3}$ in Section 1 are accepted. This goes to support the hypothesis that PE and SI influences students' behavioural intention to adopt and use e-counselling in Ghana. Meanwhile, the remaining two constructs viz. Effort Expectancy $(\mathrm{p}$ value $=.080)$ and Facilitation Condition ( $\mathrm{p}$ value $=.723$ ) are rejected given that they were found to be statistically insignificant. And this also implies that EE and FC do not influence the behavioural intention of students to use e-counselling in Ghana. Table 7 summaries the outcome of the study in line with their significance.

Table 7. Summaries of the research outcome

\begin{tabular}{lrrr}
\hline Hypothesis & P value & Significance & Remarks \\
\hline $\mathrm{H}_{1}: \mathrm{PE} \rightarrow \mathrm{BI}$ & $\mathbf{. 0 0 0}$ & significant & $\mathrm{H}_{1}$ accepted \\
$\mathrm{H}_{2}: \mathrm{EE} \rightarrow \mathrm{BI}$ & .080 & Not significant & $\mathrm{H}_{2}$ rejected \\
$\mathrm{H}_{3}: \mathrm{SI} \rightarrow \mathrm{BI}$ & $\mathbf{. 0 0 1}$ & significant & $\mathrm{H}_{3}$ accepted \\
$\mathrm{H}_{4}: \mathrm{FC} \rightarrow \mathrm{BI}$ & .723 & Not significant & $\mathrm{H}_{4}$ rejected \\
\hline
\end{tabular}

\section{B. Findings from the students' interview}

From the interview session, we found out students' eagerness to use e-counselling. In line with that, students recognised the importance of e-counselling towards their academic pursuit, though our previous study had reported the same [3]. According to the students, the ultimate outcome of our finding was the diversity in counselling methodologies through digital approach. Also, students recognised that e-counselling can afford them to access counselling at anytime and anywhere. This goes to confirm the finding from the quantitative analysis of the data from the questionnaires, where PE was found to be significant on students' behavioural intention to adopt and use e-counselling in Ghana. Regardless of the perceived benefits of using e-counselling, students had profound reservation towards its (e-counselling) implementation to the fullest in the Ghanaian context.

We deduced that the facilitating condition to motivate e-counselling was a subject of concern. From our observation, students expressed their dissatisfaction about the ban imposed on the use of their personal ICT tools such as laptops in school by the Ghana Education Service. This led to the confirmation of our previous findings [3] that students are forbidden from using their personal ICT tools on school campus. Of the numerous complaints during the session, we deduced high cost of internet bandwidth, high cost of ICT tools, and the inability of students to use e-counselling as the key reasons for the insignificance in FC for determining students' behavioural intention to adopt and use e-counselling. Through the interview session, we confirmed our thought that the Government of Ghana had supplied Laptops to students. This, according to what we discovered was an attempt by the Government to reinforce the sector with 
ICT. However, Students claimed that the supply was political.

Finally, from the interview, we discovered that students have not had any form of training in the use of ecounselling, but eagerly relishing the thought that their parents and friends would be happy for their progress through a well-defined guidance (counselling) program. This affirms the reason for the significance of SI on BI. Meanwhile, from the interactive session, we realised that culture (context) and trust were also key factors that could determine students' behavioural intention to adopt and use e-counselling. Further empirical analysis ought to be conducted to ascertain their effect on BI to use ecounselling.

\section{DISCUSSION}

ICT has increased the flexibilities and as well reduced the challenges of reaching out many students regarding counselling delivery. Different students may have different needs at different stages of their studies, and thus require different counselling approaches (blended counselling) for support. Reference [7] believe that individuals might need support at each stage of their development. Some may need counselling assistance to cope with their life challenges in school. Others may also need counselling to overcome barriers that prevent them from finishing a stage in life and enter into a new developmental stage [28]. Reference [30] identified family-related matters, bullying, behavioural and emotional problems, depression, self-harm and suicide, and mental health issues as areas of concern. Those areas are the potential sources of problems that confront students in their academic pursuit. Also, reference [30] reported that these challenges could affect their relationships with peers at school, and even outside, including their families and their engagement with education. In this way, reference [28] showed that counselling support could take many forms, and this may come from the administrators, teachers and fellow students (peer counselling). Of these benefits, diversifying counselling delivery becomes a necessity. Meanwhile, quite a few research has been conducted in this area to motivate e-counselling in Ghana. Notable among the researchers is [11] who undertook a study to investigate counselling requirements at the University level. The study identified common ICT-support requirements such as anonymous capabilities and video conferencing capabilities in Ghana. In a related study, [3] also carried out a study to investigate the state of counselling technologies in Ghana. The researchers discovered email as the only used e-counselling tool in counselling delivery.

In this study, we investigated the predictive (motivational) factors that determine students' behavioural intention to adopt and use e-counselling in Ghana. Initially, UTAUT model was validated through Cronbach alpha to ascertain the internal consistency of the test items. The validation yielded an overwhelming reliability $(87.8 \%)$ of the test items collected through questionnaire. After that MLR analysis performed on the data found Performance Expectancy (PE) as the most predictive (motivational) factor for students' behavioural intention to adopt and use e-counselling. Similar to [31] and [32] who also found performance expectance in mobile learning as the most predictive factor. Students recognised the importance of e-counselling in their academic orientation. As reported by the students, the ultimate finding was the diversity in counselling methodologies through digital means. This goes to confirm the first hypothesis that e-counselling would improve students' academic performance and holistic life development. Social Influence (SI) was the second most predictive factor found to trigger students to adopt and use e-counselling. This implies that students perceive that close allies would believe that they should use ecounselling in order to improve on their academic and career development. This also goes to confirm the outcome of the interview that people (parents, teachers and friends) who influence their behaviour would believe that using e-counselling could improve their routine counselling services. In contrast, Wang (2009) and Mbete \& Raisamo (2014) found SI significant but had the lowest significance.

Effort Expectancy (EE) and Facilitation Condition (FC) are the two constructs that do not influence students' behavioural intention to adopt and use e-counselling. Effort Expectancy is the degree of simplicity associated with the use of e-counselling system. The reason for the insignificance may be attributed to the fact that none of the respondents gave positive response to having had training nor use e-counselling for counselling session. This goes to confirm [9] study which concerns ICT in developing countries. They reported that challenges to implement ICT to the fullest can be attributed to lack of skilled human resources and perceived difficulty in ICT integration [9]. Facilitation Condition (FC) was found to be the lowest of the insignificant predictive factor for students' behavioural intention to adopt and use ecounselling. This implies that students believe there is no organizational and technical infrastructure to support the use of e-counselling system in Ghana. This goes to confirm the claim that counselling units in the SHSs lack the needed infrastructure and tools to motivate ecounselling $[3,11]$ though the Government is putting an effort to augment the SHS sector.

\section{CONCLUSION AND FUTURE STUdIES}

The motivation to encourage designers to be effective in the implementation ICT into counselling crucially depends on the behavioural intention of potential users, especially students' willingness to adopt and use ICT. This intention necessitated this study and prompted the need for adopting UTAUT model in this study. We estimated the internal consistencies of all the test items based on UTAUT constructs. The study revealed a good internal consistency of the data. Subsequently, MLR analysis performed on the data found Performance Expectancy and Social Influence as the influencing 
factors while Effort Expectancy and Facilitation Condition came out insignificant to students' behavioural intention towards technology acceptance and use. In effect, the contribution of this paper is to create awareness to e-counselling researchers as to what factors influence the behavioural intention of students to accept and use e-counselling in Ghana. From the interactive session, we realised that culture (context) and trust are key factors to determine students' behavioural intention to adopt and use e-counselling. Further empirical analysis ought to be conducted, of which we shall consider in the future.

The relevance of this study is to use the findings as a base to build an e-counselling system in the future. We intend to leverage Natural Language Processing to build automated e-counselling system for emotion and sentiment analysis to aid in counselling delivery in Ghana. The platform shall have the capability of helping students to contact counsellors, thereby getting students to appreciate and use the intended platform. Hence, this study would inform the kind of features that need to be incorporated into the intended platform. For instance, relevant features with likely impact on students' academic development would be a key, since students have demonstrated in this study that performance expectancy is a significant factor to use e-counselling system in Ghana. Students, parents and staff of Senior High Schools shall be involved in the development of the intended platform, since students have also demonstrated through the level of significance of SI that family and other people would support and appreciate them using ecounselling system.

\section{AKNOWLEDGMENT}

We wish to acknowledge University of Eastern Finland foundation for sponsoring this paper financially. The support of the staff and students of AGASS, BPRESEC and KASS is deeply appreciated for cooperating in the data collection. We are also grateful to Samuel Adjei Konadu and Michael Osei Barima for their immense contribution towards collecting and coding of the raw data.

\section{REFERENCES}

[1] V. Venkatesh, M.G Moris, G.B Davis, F.D. Davis, "User Acceptance of Information Technology: Toward a Unified view", MIS Quarterly, vol. 27 No.3, pp 425-478, 2003.

[2] J. K Essuman, "A review of Educational studies in Guidance and counselling in schools in Ghana". Ghana journal of Psychology, vol.1, no. 1, pp 2-88, 2001.

[3] E.A. Kolog, E. Sutinen, M. Vanhalakka-Ruoho,"Ecounselling implementation: Students' life stories and counselling technologies in perspective", International Journal of Education and Development using Information and Communication Technology (IJEDICT), Vol. 10, Issue 3, pp. 32-48, 2014.

[4] P. A. Landers, D. A Nancy, M. Aleman, M. M. Silano and W. Turek "A guide to comprehensive school counselling program: Development of Connecticut school comprehensive counselling. 2008. Available at
<http://www.sde.ct.gov/sde/lib/sde/PDF/DEPS/Special/cou nselling.pdf.> Accessed on [3rd July 2013]

[5] Ghana Education Service, "Teacher's guide on the preventive of drug abuse in schools" Prevention of Drug Abuse Unit, Division for the Renovation of Educational Curricula and Structures, UNESCO, 1995 Available from: $<\quad$ www.unesco.org/education/pdf/332_55.pdf > Assessed on [23 March 2013].

[6] S. Wardell "History of online counselling", 2008 Available on: <http://ezinearticles.com/?History-ofOnline-Counselling-and-Child-Development\&id=1049584 > Accessed on [7th July 2014].

[7] V. R. Esbroeck, "Career Guidance in a global world. International handbook of career guidance. Springer science", 2008. Business media.

[8] J.C. Aker and M.I. Mbiti, "Mobile phones and economic development in Africa. Journal of Economic Perspectives", 24(3), 207-232, 2010.

[9] J. Errera, W. Roestenburg and C. Rensleigh, "Ecounselling at university of Johannesburg: A pilot program", International Review of Social Sciences and Humanities. 3, 24-35, 2012.

[10] D. Kessy, M. Kaemba, and M. Gachoka, "The reasons for under use of ICT in education: In the context of Kenya, Tanzania and Zambia" Paper presented at the 4th IEEE International Workshop on Technology for Education in Developing Countries, Iringa, Tanzania, 2006.

[11] M.O Kevor 'e-Counselling for Institution of higher learning in Ghana: What are the requirements?", International Journal of research in Computer application and management, Vol 3. No. 5 pp. 131-134, 2013.

[12] Z. Wang, H. Chen, R, Xin, and C. Yi,“ Peer counselling” International Conference on Educational and Information Technology (ICEIT)", 2010

[13] T. Khandelwal, G. Joshi, A. Singhania, A. Dutta "Semantic Web-Based E-Counselling System", 2013, International Journal of Computer Science and Electronics Engineering (IJCSEE) Volume 1, Issue 1, ISSN 2320-4028

[14] G.W. Brown, "Social work and social services web sites" 2011 [http://gwbweb.wustl.edu/resources/] Accessed on $3^{\text {rd }}$ March 2015.

[15] D.F., Tate, E.H., Jackvony \& R.R.,Wing 'Effects of internet behavioural counselling on weight loss in adults at risk for type 2 diabetes: A randomized trial'. Journal of the American Medical Association, vol. 289 no.14, pp.18331836, 2003.

[16] I. Shiller "Online Counselling: A review of the literature". www.emys.on.ca/pdfs.../onlinecounselling_literaturerevie w.pdf. Accessed on 24th November 2013.

[17] NERIC Secretariat, 'Education Reform 2007 at a glance'. Available from: http://planipolis.iiep.unesco.org/upload/Ghana/Ghana_edu cation_reform_2007.pdf Accessed on [4th August 2013].

[18] S. Attuqueyfio and H. Addo, "Review of studies with UTAUT as conceptualize framework" European Scientific Journal edition vol.10, No.8, pp. 249-258, 2014.

[19] T. Sundaravej "Empirical Validation of Unified Theory of Acceptance and Use of Technology Model", College of Business Administration, University of Missouri at Saint Louis, 2009.

[20] S. Deng, Y. Liu, and Y. Qi, "An empirical study on determinants of web based question-answer services adoption", online information Review, vol. 35, No. 5, pp 789-798, 2011.

[21] J.T. Marchewka, C. Liu and K. Kostiwa, "An Application of the UTAUT Model for Understanding Student 
Perceptions Using Course Management Software, Vol. 7 Issue 2, pp 93-104, 2007.

[22] Y. Cheng, T. Yu, C. Huang, C. Yu and C. Yu, "The Comparison of Three Major Occupations for User Acceptance of Information Technology: Applying the UTAUT Model," business, Vol. 3 No. 2, pp. 147-158, 2011doi:10.4236/ib.2011.32021

[23] E. AbuShanab., J.M Pearson J. "Internet banking in Jordan: The unified theory of acceptance and use of technology (UTAUT) perspective", Journal of Systems and Information Technology, Vol. 9 Issue: 1, 2007.

[24] C. Martins, O. Tiago and P. Ale "Understanding the Internet Banking adoption: A Unified theory of acceptance and use of technology and perceived Risk application", International Journal of Information Management, Vol. 34, Issue 1, pp. 1-13, 2013.

[25] L.J. Cronbach. Essentials of Psychological Testing. Harper \& Row. 1970, p. 161.

[26] J.D. Brown, "The Cronbach alpha reliability estimate" JALT Testing \& Evaluation SIG Newsletter, vol. 6, Issue 1 pp. $17-18,2002$.

[27] J., Nunnally "Psychometric theory", New York, NY: McGraw, 1978.

[28] T. Pyrstöjärvi, T. Saramäki, Blended counselling a means of supporting students. University of Eastern Finland, 2011.L

http://primus.archimedes.ee/conference2011/abs/short/Sara maki_Pyrstojarvi.pdf Accessed on [24th November 2013].

[29] J.P Li and R. Kishore, "How Robust is the UTAUT Instrument? A Multigroup Invariance Analysis in the Context of Acceptance and Use of Online Community Weblog Systems", 2006, Proceeds of SIGMISCPR'06, Claremont, California, USA, April 2006.

[30] L. Phillips and R. Smith, "Developing school counselling services for children and young people in Wales", National Foundation for Educational Research, 2011 report.

[31] Y.S., Wang \& Shih, Y.W. Shih, "Why Do People Use Information Kiosks? A Validation of the Unified Theory of Acceptance and Use of Technology". Government Information Quarterly, vol.26, pp.158-165, 2009.

[32] J.S. Nbtebe and R. Raisamo, "Investigating students' behavioral intention to adopt and use mobile learning in higher education in East Africa", International Journal of Education and Development using Information and Communication Technology (IJEDICT), , Vol. 10, Issue 3, pp. 4-20, 2014.

[33] M. Kokaleva, I. Stojanovic and Z. Zdravev, "Model of eLearning Acceptance and Use for Teaching Staff in Higher Education Institutions", International Journal of Modern Education and Computer Science, Vol. 4, No. 23-31, 2015.

\section{Authors' Profiles}

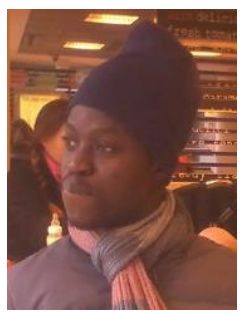

Awuni Emmanuel Kolog received his Master`s degree in Computer Science from the University of Eastern Finland. He is currently a $\mathrm{PhD}$ Candidate at the same University. Emmanuel's research is mainly focused on leveraging Natural Language Processing for counselling. His research is primarily focused on extracting, analysing and visualizing of emotions from students life stories, in order to form the basis to explore contextualized digital counselling platforms. His research interests span across contextualized e-counselling implementation, User-cantered design, Natural Language Processing for emotion detection, Game design based on life stories, ICT4D and educational technologies.



Prof. Erkki Sutinen received his $\mathrm{PhD}$ in Computer Science from the University of Helsinki. $\mathrm{He}$ is the leader of the Interaction Design group at the University of Turku. He is also the founder of the EdTech research group at the University of Eastern Finland. He is a specialist in the field of educational technology and ICT for development. He is also the founder of international online $\mathrm{PhD}$ program: IMPDET at the University of Eastern Finland. Prof. Sutinen's research interests include technologies for special education, contextualized IT education, visual and textual tools for learning, and natural language processing methods for business intelligence and for emotion detection. For these, he supervises and collaborates with several $\mathrm{PhD}$ students and educational institutions.

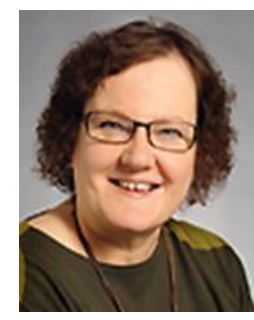

Prof. Marjatta Vanhalakka-Ruoho received her $\mathrm{PhD}$ from University of Tampere in the field of Psychology. She acts as professor in career counsellor Education in the University of Eastern Finland. Career counsellor education carries out the following educational programs: Degree Programme in Career Counselling, Master's Degree Programme in Career Counselling and Qualification studies for Career Counsellors. Her research work has dealt with family, occupational aspirations, organizational development and career counselling. The present research themes are group counselling, educational transitions and the family and enhancing agency in transitions.

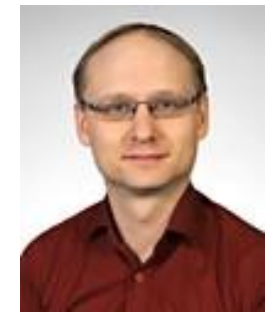

Dr. Jarkko Suhonen received his $\mathrm{PhD}$ in Computer Science from the University of Joensuu in 2005 . He currently holds a senior researcher position at the school of Computing of the University of Eastern Finland. His main academic interests are related to design science research in educational technology, computer science education, blended learning solutions in Computer Science and ICT for Development. Dr. Suhonen has more than 10 years of experiences in developing, managing and evaluating online study programmes in Computer Science. Dr. Suhonen has published more than 50 peer-reviewed scientific articles.



Ebenezer Anohah is a doctoral student at the University of Eastern, Finland with computer science major and a passion for using mobile technologies to enhance teaching and learning in computer science education. His doctoral work involves the use of indigenous cultural approaches to learn computer science education and explore the underlying learning models at high school level in developing country context 
How to cite this paper: Emmanuel Awuni Kolog, Erkki Sutinen, Marjatta Vanhalakka-Ruoho, Jarkko Suhonen, Ebenezer Anohah,"Using Unified Theory of Acceptance and Use of Technology Model to Predict Students' Behavioral Intention to Adopt and Use E-Counseling in Ghana", IJMECS, vol.7, no.11, pp.1-11, 2015.DOI: 10.5815/ijmecs.2015.11.01 